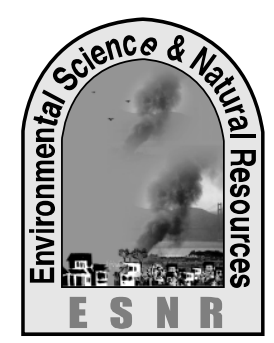

\title{
Spatial Variability of Rice Grain Arsenic in Confined and Unconfined Basins of Ganges River Floodplain Soils of Bangladesh
}

\section{H. Kabir ${ }^{1}$, G. K. M. M. Rahman ${ }^{1^{*}}$, Z. U. Ahmed ${ }^{2}$, M. M. Rahman' and M. M.} Rahman $^{3}$

\author{
${ }^{1}$ Department of Soil Science, Bangabandhu Sheikh Mujibur Rahman Agricultural \\ University (BSMRAU), Bangladesh \\ ${ }^{2}$ The International Maize and Wheat Improvement Centre (CIMMYT), Dhaka, \\ Bangladesh \\ ${ }^{3}$ Department of Entomology, Bangabandhu Sheikh Mujibur Rahman Agricultural \\ University (BSMRAU), Bangladesh \\ *Corresponding author: mustafiz@bsmrau.edu.bd
}

\begin{abstract}
Arsenic (As) accumulates in rice grain from contaminated irrigation water and soils may vary with the land types and water receiving basins. Two confined and one unconfined basins comprised of different land types in the As contaminated Ganges River Floodplain soils of Faridpur district of Bangladesh were selected to assess the contribution of different land types on spatial distribution of As uptake by rice grain. Sites in Faridpur Sadar and Madhukhali upazilas were confined basins, while a third site in Boalmari upazila was an unconfined basin connected to a river. Each site consisted of a mosaic of between 16-31 shallow tube well (STW) irrigation command areas with water As concentrations ranging from about 20 to $170 \mu \mathrm{g}^{-1}$ in Faridpur and Boalmari sites and $20-110 \mu \mathrm{g}^{-1}$ in Madhukhali site. Soil arsenic concentrations ranged from about 4-42, 5-31 and 5-29 mg kg-1 in Madhukhali, Faridpur Sadar and Boalmari, respectively, while the resultant rice grain As were $0.22-0.69,0.095-0.751$ and $0.030-0.92 \mathrm{mg} \mathrm{kg}^{-1}$, respectively. Arsenic concentrations in rice grain of different sites were in the order of Madhukhal>Faridpur Sadar>Boalmari basin. Arsenic accumulated high in the confined basins because of its less mobilization while more mobilization and loss of As in the open unconfined basin was obvious which materialized in the rice grain arsenic of the corresponding study sites.
\end{abstract}

Key words: Arsenic, Land types, Rice grain, Variability

\section{Introduction}

Arsenic (As) is one of the most poisonous elements due to its impending risk to biomes and human being (Naidu, 2006). Arsenic accumulation in agricultural soils and irrigation water of Bangladesh mainly occurs by geological processes. Arsenic bearing minerals originated from the Himalayas flowing through Ganges river water and outspread up to West Bengal of India and Bangladesh. Arsenic bearing minerals are being deposited in shallow aquifers of the Ganges River Floodplain areas and thereby increased ground water contamination. At present, the farmers of Bangladesh cultivate HYV boro rice due to meet up huge amount of food for such large population. The HYV boro rice requires a large volume of irrigation water because it cultivates in dry season. Arsenic build up in agriculture soils of Bangladesh gradually increased with increasing the arsenic contaminated irrigation water over time (Rahman et al., 2005; Panaullah et al., 2009; Dittmar et al., 2010 and Ahmed et al., 2011). Ahmed et al. (2011) reported that $0.1 \mathrm{mg}^{-1}$ As containing $1 \mathrm{~m}$ depth of irrigation water to a single rice crop build up soil As about $0.5 \mathrm{mg} \mathrm{kg}^{-1}$ in the top $15 \mathrm{~cm}$ of soil in a shallow tube well (STW) command area. Actually, As deposition in soil through contaminated irrigation water is not uniform because of As precipitates as arsenic-iron oxide complexes during water flow through irrigation channel and across the field (Ahmed et al., 2011). As a result, uneven arsenic distribution occurs in a STW command area (Islam et al., 2012). On the other hand, it was reported by Brammer (1999) that As retention might be varied in different land types of water receiving basin areas. The Ganges River Floodplain comprised of broad ridges and basins. The basins are further classified into confined and unconfined areas and flood usually occurs in the confined basins by monsoon rain, while for unconfined basins are flooded by river flow. The basin areas receive water along with different nutrients and heavy metals, especially As from the surrounding ridges. It is hypothesized that confined basins accumulate more As than that of unconfined basins. Arsenic accumulation in paddy field soil depends on land types under different rive basins is a great concern. Different geostatistical interpolations or kriging have already been applied to understand spatial distribution mapping for As risk assessment (Gaus et al., 2003; Serre et al., 2003; Yu et al., 2003) but mapping of paddy soil As and its uptake into rice grain with or without incorporating environmental variables in respect of land types has not yet been done. Therefore, present study was aimed to assess the influence of different land types of confined and unconfined basins on spatial distribution of As uptake by rice grain in the As contaminated Ganges River Floodplain soils of Bangladesh.

\section{Materials and Methods}

\section{Study area}

The study was conducted in three locations of Faridpur district, the south central part of Bangladesh (Fig. 1). This part of the country has already been identified as highly arsenic. contaminated areas regarding to groundwater (BGS/DPHE, 2001) and paddy soil (Rahman et al., 2005). These three sites were selected according to the variation of land types and soil morphology (Table 1). Two confined basins were located at Sachia, Faridpur Sadar and Mirzakandi, Madhukhali upazila. Conversely, the open or unconfined basin was located at Satoir, Boalmari, which is open and connected to a river. The land types 
of two confined basins were medium high to very low (Faridpur Sadar) and high to low (Madhukhali), while for the unconfined basin (Boalmari) land type was medium high to very low.

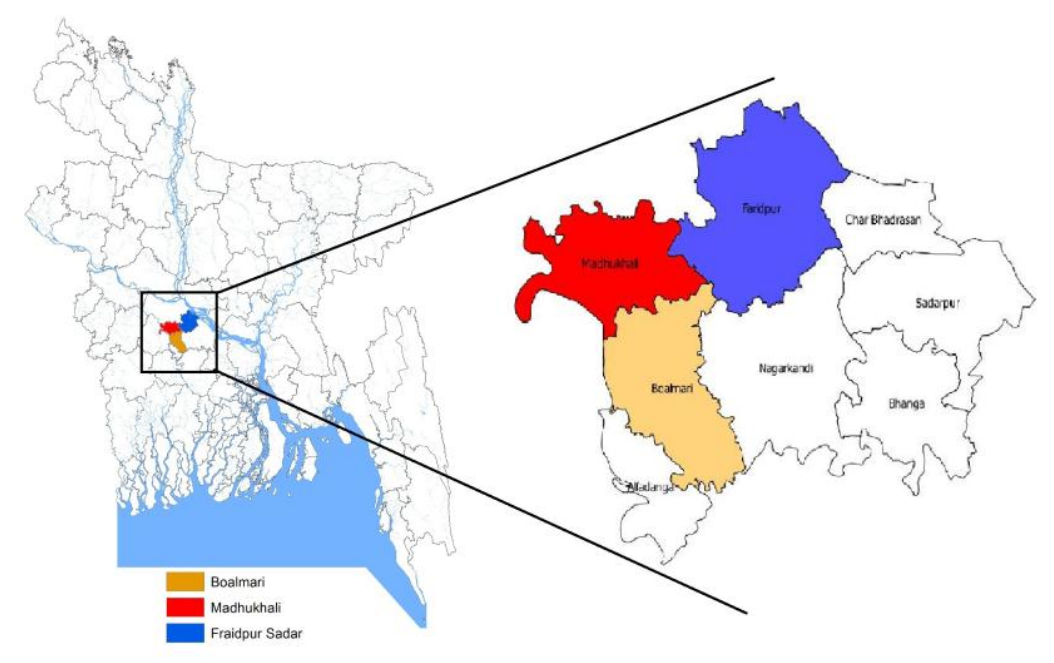

Fig. 1. Map of Bangladesh showing the study areas of Faridpur district

The selected sites are exclusively used for the production of boro rice since the installation of the local irrigation wells in the early 1990s. The irrigation well generally extracts groundwater from a depth of 60-105, 70-110 and 60-175 ft in Boalmari, Madhukhali and Faridpur Sadar upazila, respectively. Fields are irrigated at a time until covered by $3-10 \mathrm{~cm}$ of water. Over the next days the water level gradually decreases until the moist soil surface is exposed. Scattered depressions filled with water may still be presented in parts of the field, while soil cracks form in other parts. Fields are thus subjected to periodic flooding and drying. Mainly arsenic in these soils have been build up by using contaminated irrigation water, which has already been identified by BGS/DPHE (2001) and Rahman et al., (2005).

Table 1: General information of study sites

\begin{tabular}{|c|c|c|c|c|}
\hline Physiography & Union & $\begin{array}{c}\text { Land type \& flooding } \\
\text { condition }\end{array}$ & Soil series & Major cropping pattern \\
\hline \multicolumn{7}{|c|}{ Madhukhali } \\
\hline $\begin{array}{c}\text { Old Ganges river } \\
\text { floodplain soil }\end{array}$ & Bagat & $\begin{array}{c}\text { highland to lowland \& } \\
\text { confined basin }\end{array}$ & Sara and Gopalganj & $\begin{array}{c}\text { Jute-rice-wheat, jute-rice-rice, and } \\
\text { jute-rice-onion }\end{array}$ \\
\hline \multicolumn{7}{|c|}{ Faridpur Sadar } \\
\hline $\begin{array}{c}\text { Old Ganges river } \\
\text { floodplain soil }\end{array}$ & Sachia & $\begin{array}{c}\text { medium highland to very } \\
\text { lowland \& confined basin }\end{array}$ & $\begin{array}{c}\text { Gopalganj, Iswardi } \\
\text { and Ghior }\end{array}$ & $\begin{array}{c}\text { Boro-jute-fallow and Robi crops- } \\
\text { jute-T.aman }\end{array}$ \\
\hline \multicolumn{7}{|c|}{ Boalmari } \\
\hline $\begin{array}{c}\text { Old Ganges river } \\
\text { floodplain soil }\end{array}$ & Satoir & $\begin{array}{c}\text { medium highland to very } \\
\text { lowland \& unconfined } \\
\text { open basin }\end{array}$ & $\begin{array}{c}\text { Sara, Gopalganj and } \\
\text { Iswardi }\end{array}$ & $\begin{array}{c}\text { Jute-fallow-rice, Vegetables-rice- } \\
\text { onion, and Fallow-fallow-rice }\end{array}$ \\
\hline
\end{tabular}

source: Soil Resource Development Institute (SRDI), Bangladesh, 2005

\section{Sample collection}

Rice grains were collected in the boro season 2013 from the selected sites of three upazillas for As analysis. Green circles representing rice grain sampling points (Fig. 2). A number of 104, 20 and 77 rice grain samples were collected from Faridpur Sadar, Madhukhali and Boalmari upazilla respectively. It was observed that boro rice grown across the command areas except Madhukhali because of land type. The land types of Madhukhali are identified as high to low. Farmers can grow only boro rice in the low land areas (Fig. 2) while wheat, lentil including vegetables are grown in the other parts of the command areas.

\section{GPS record of sampling point}

All selected sampling points were geo-referenced by a GPS (Global Positioning System). GPS reading of all sampling points were recorded using GPS device (Model: Garmin 60CSx). 


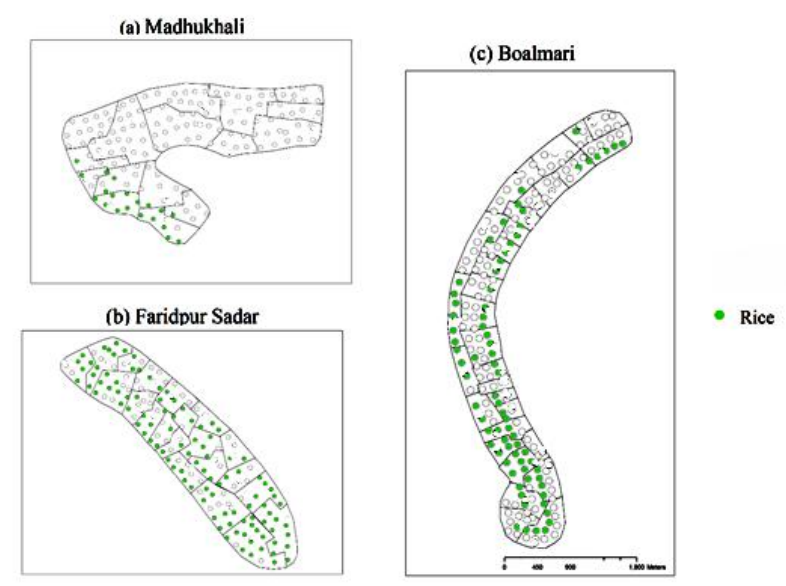

Fig. 2. Study areas showing the rice samples collection points

\section{Sample preparation for as analysis}

Rice grain samples were de-husked, dried and homogenized with Vibrating Sample Mill, HEIKO TI200. All samples were digested by nitric $\left(\mathrm{HNO}_{3}\right)$ perchloric $\left(\mathrm{HClO}_{4}\right)$ acid digestion (Norvell et al., 2000 ; Jacobs et al., 1970) with the block digester (Modelbehrotest K24 Digestion Unit). For maintaining the analytical quality rice flour digestion certified reference material (NIST 1568a) was run with each set of samples. All samples were pre-reduced with potassium iodide and ascorbic acid to reduce As (V) to As (III) prior to determination of As by hydride generation atomic absorption spectrophotometer (Buck Scientific 210 VGP) with continuous flow hydride generation system (HG-AAS). The standards were prepared following the same analytical matrix as followed for grain sample preparation. The desired and reasonable standard solutions were prepared to prepare a standard calibration curve.

\section{Statistical analysis}

Statistical analyses including coefficient of variation (CV) and analysis of variance (ANOVA) were performed using $\mathrm{R}$ statistical software (Version 2.15.2, 2012-10-26).

\section{Geostatistical analysis}

The gstat package (Pebesma, 2004; Pebesma and Wesseling, 1998) in the $\mathrm{R}$ statistical computing environment, QGIS and ArcGIS software were used for all geostatistical analysis and visualization of map outputs. It was also used to prepare the map of spatial patterns of As in command research area.

\section{Results and Discussion}

The toposequences of three study sites in the Ganges River Floodplain comprised of highland to very lowland with each of the command area covering about 30-40 ha (Table 1). The soils of the study region were loam in the ridges and clay in the basins. The Ganges Floodplain soils are predominantly calcareous in nature having $\mathrm{pH}$ ranged from 6.9 to 8.4 which was neutral to slightly alkaline. As per soil fertility ranking of BARC (2012) the general fertility of the study area was found low to medium. Phosphorus in soils were found very low to high, while iron contents were medium to very high (Table 2). Phosphorus and iron contents in soils of the study area might have significant contribution to As mobility in soils and thereby uptake by rice. Organic matter contents were low in the ridges, while medium to high in the basins (Table 2). Each site consisted of a mosaic of between 16 and 31 shallow tube well (STW) irrigation command areas with high water As concentrations ranging from about $0.020-0.170 \mu \mathrm{gL}^{-1}$ at the Faridpur and Boalmari sites and 0.020-0.110 $\mu \mathrm{gL}^{-1}$ at the Madhukhali site. Soil arsenic concentrations ranged from 4-42 $\mathrm{mg} \mathrm{kg}^{-1}$ at Madhukhali, 5-31 $\mathrm{mg} \mathrm{kg}^{-1}$ at Faridpur Sadar and 5-29 $\mathrm{mg} \mathrm{kg}^{-1}$ at Boalmari (Table 2). Although a critical level for soil As is not established in Bangladesh but several research studies have found reductions in rice yields when soil As levels exceed $20 \mathrm{mg} \mathrm{kg}^{-1}$ (Biswas 2009; Rauf, 2009). Biswas and Rauf (2009) also reported not only rice yield reduction from arsenic toxicity but also incremental concentrations of As in rice grain. The spatial distribution of rice grain As in different land types of confined and unconfined basins were influenced by STW water and soil arsenic (Fig. 3 - 5). In our present study, rice grain As were ranging from $0.22-0.69$, $0.095-0.751$ and $0.030-0.92 \mathrm{mg} \mathrm{kg}^{-1}$ with the mean value of $0.44,0.368$ and $0.31 \mathrm{mg} \mathrm{kg}^{-1}$ at Madhukhali, Faridpur Sadar and Boalmari, respectively (Table 3). The rice grain As at Madhukhali and Faridpur Sadar were comparatively higher than rice grain As at Boalmari. Lower level of arsenic in rice grain of Boalmari upazila was the attributed by normal flooding condition in the rice growing season where minimum irrigation was needed and hence less amount of As was accumulated in soils and thereby resultant As translocation to grain was also less. These results are consistent with greater retention of arsenic in soils where uncontrolled flooding over bunds that define fields is the least, leading to less mobilization and movement of arsenic from high lands and confined basins and greater mobilization, movement and loss of arsenic from low lands and unconfined basins (Rahman et al., 2013). Thus grain As was found higher in confined basins as compared to unconfined basin might be due to positive relationship occurred between soil As and rice grain As. That means, rice grain As observed higher in high level of soil As in confined basins than low level of soil As in unconfined basin. The findings of our study regarding the relationship between soil As vs grain As is in agreement with the findings of Ahmed et al., (2003). 
Table 2. Physicochemical properties of soil of the study sites

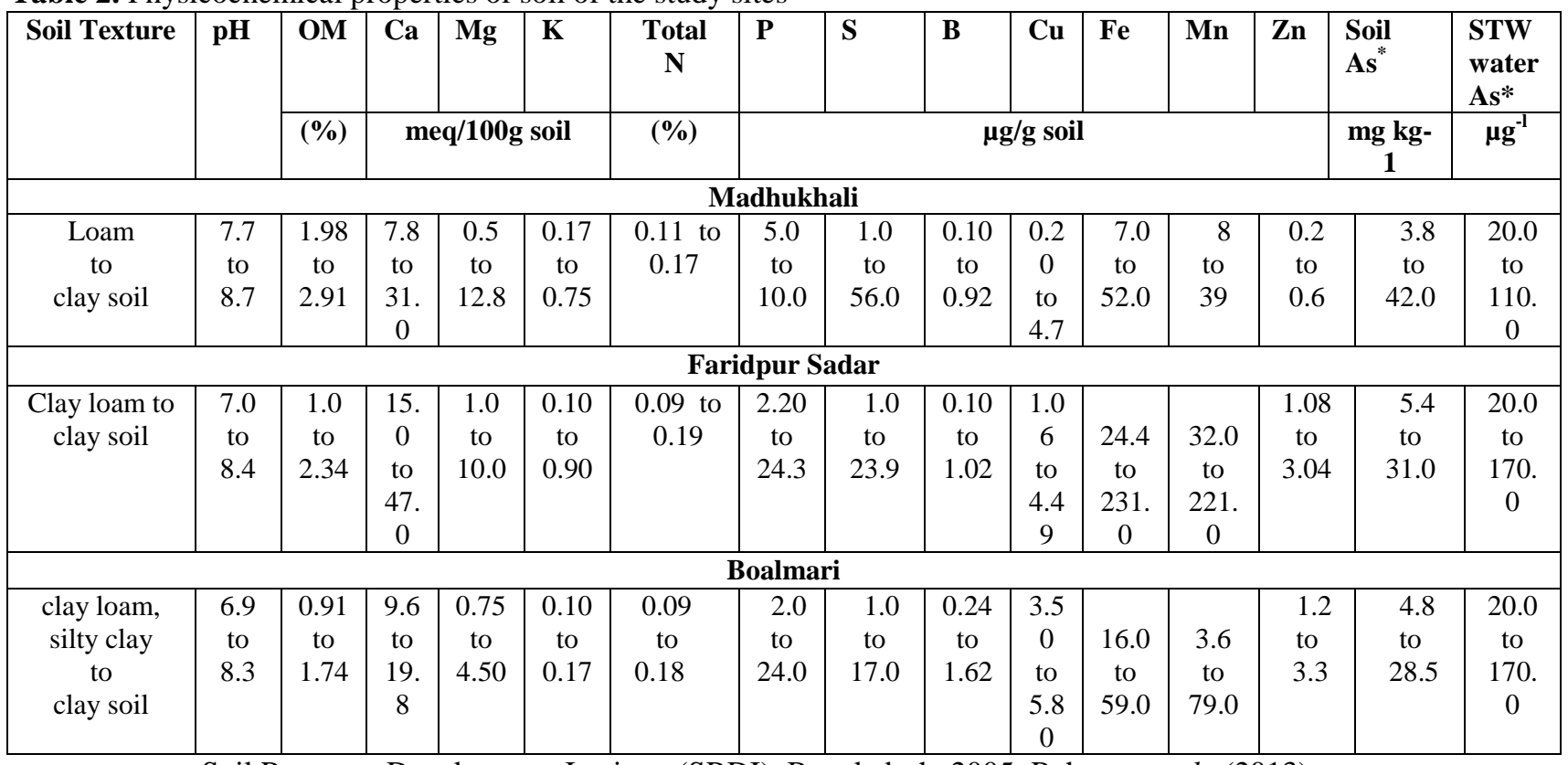

source: Soil Resource Development Institute (SRDI), Bangladesh, 2005, Rahman et al., (2013)

Table 3. Descriptive statistics of arsenic concentration in rice grain.

\begin{tabular}{|l|l|l|l|}
\hline $\begin{array}{l}\text { Statistical } \\
\text { parameter }\end{array}$ & \multicolumn{3}{|l|}{ Rice grain As } \\
\cline { 2 - 4 } & Madhukhali & $\begin{array}{l}\text { Faridpur } \\
\text { Sadar }\end{array}$ & Boalmari \\
\hline $\begin{array}{l}\text { Mean } \\
\text { kg-1 })\end{array}$ & 0.44 & 0.368 & 0.31 \\
\hline $\begin{array}{l}\text { Max. } \\
\text { kg-1 })\end{array}$ & 0.69 & 0.751 & 0.92 \\
\hline $\begin{array}{l}\text { Min. } \\
\text { kg-1 })\end{array}$ & 0.22 & 0.095 & 0.030 \\
\hline $\mathrm{CV}(\%)$ & 29.55 & 42.12 & 58.06 \\
\hline $\mathrm{SD}$ & 0.13 & 0.155 & 0.18 \\
\hline
\end{tabular}

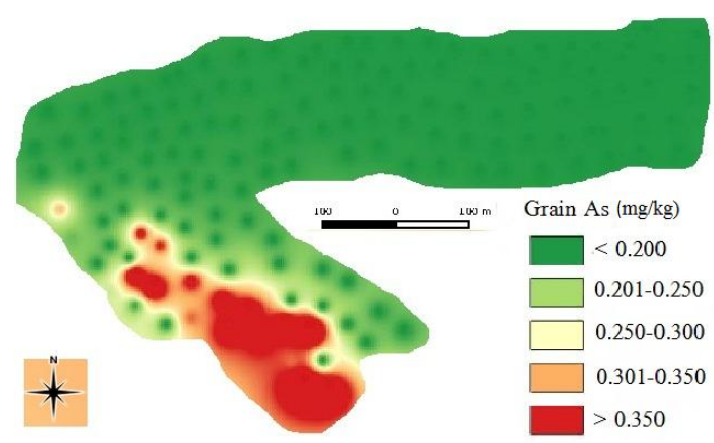

Fig. 3. Spatial distribution of rice grain arsenic concentration $\left(\mathrm{mgkg}^{-1}\right)$ at Madhukhali.

\section{Conclusions}

The average rice grain As was higher in confined basins as compared to unconfined basin. These results are consistent with greater retention of arsenic in soils where uncontrolled flooding over bunds that define fields is the least, leading to less mobilization and movement of arsenic from high lands and confined

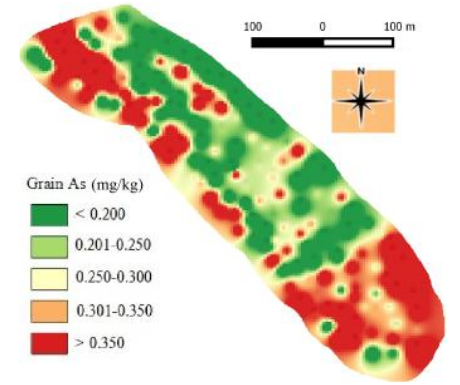

Fig. 4. Spatial distribution of rice grain arsenic concentration $\left(\mathrm{mgkg}^{-1}\right)$ at faridpur Sadar

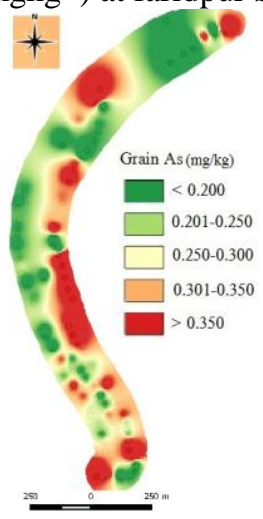

Fig. 5. Spatial distribution of rice grain arsenic concentration $\left(\mathrm{mgkg}^{-1}\right)$ at Boalmari

basins and greater mobilization, movement and loss of arsenic from low lands and unconfined basins. Thus nice plant can take more As from confined basins soils than unconfined basin soils.

\section{Acknowledgments}

We acknowledge the authors of previous works on spatial distribution of soil and water As (Arsenic) from the same sites (Rahman et al., 2013) and Soil Resource 
Development Institute (SRDI) of Bangladesh for providing soil nutrient data.

\section{References}

Ahmed, Z. U.; Panaullah, G. M.; Rahman, M. S. 2003. Arsenic in irrigation waters, soils and rice grains in some areas of Bangladesh. Proceeding of the 7 th International Conference on the Biochemistry of Trace Elements, June 15-19, Uppsala, Sweden.

Ahmed, Z. U.; Duxbury, J. M.; DeGloria, S. and Panaullah, G. M. 2011. Factors affecting paddy soil arsenic concentration in Bangladesh. Prediction and uncertainty of geostatistical risk mapping. Science of The Total Environment, 412-413, 324-335.

BGS/DPHE (British Geological Survey/Department of Public Health Engineering), 2001. Executive summary of the main report of Phase 1, Groundwater Studies of Arsenic Contamination in Bangladesh, by British Geological Survey and Mott MacDonald (UK) for the Government of Bangladesh, Ministry of Local Government, Rural Development and Cooperatives. Department of Public Health Engineering and Department for International Development (UK).

Biswas, M. H. R. 2009. Response of Rice Varieties and Vegetables Crops to Different Levels of Soil Arsenic. (Ph.D. Thesis). Department of Soil Science, Bangabandhu Sheikh Mujibur Rahman Agricultural University, Gazipur, Bangladesh.

Brammer, H. 1999. Floods in Bangladesh: geographical background to the 1987 and 1988 floods. Geogr J. $156,12-22$.

Dittmar, J.; Voegelin, A.; Maurer, F.; Roberts, L. C.; Hug, S. J. and Saha, G. C. 2010. Arsenic accumulation in a paddy field in Bangladesh: seasonal dynamics and trends over a three-year monitoring period. Environ Sci Technol. 44, 292531.

Gaus, I.; Kinniburgh, D. G.; Talbot, J. C.; Webster, R. 2003. Geostatistical analysis of arsenic concentration in groundwater in Bangladesh using disjunctive kriging. Environ Geol. 44, 939-48.

Islam, M. R.; Brammer, H.; Rahman, G. K. M. M.; Raab, A.; Jahiruddin, M.; Solaiman, A.R.M.; Meharg, A. A. and Norton, G. J. 2012. Arsenic in Rice Grown in Low-Arsenic Environments in Bangladesh. Water Qual Expo Health. 4,197-208.

Jacobs, L.W.; Keeney, D. R. and Walsh, L. M. 1970. Arsenic residue toxicity to vegetable crops grown on Plainfield sand. Agron. J. 62, 588-591.

Naidu, R.; Smith, E.; Owens, G.; Bhattacharya, P. and Nadebaum, P. 2006. Managing Arsenic in the Environment from Soil to Human. CSIRO Publishing, Melbourne, Australia.

Norvell, W. A.; Wu, J.; Hopkins, D. G. and Welch, R. M. 2000. Association of cadmium in durum wheat grain with soil chloride and chelate-extractable soil cadmium. Soil Sci. Am. J. 64, 2162-8.

Panaullah, G. M.; Alam, T.; Hossain, M. B.; Loeppert, R.H.; Lauren, J.G.; Meisner, C.A.; Ahmed, Z.U. and
Duxbury, J.M. 2009. Arsenic toxicity to rice (Oryza sativa L.) in Bangladesh. Plant and Soil. 317, 31-39.

Pebesma, E. J. 2004. Multivariable geostatistics in S: the gstat package. Comput. Geosci. 30, 68391.Pebesma, E.J.; Wesseling, C.G. 1998. Gstat: a program for geostatistical modelling, prediction and simulation. Comput. Geosci. 24, 17-31.

Rahman, G. K. M. M.; Panaullah, G. M.; Loeppert, R. H.; Duxbury, J. M.; Meisner, C. A.; Biswas, B. K. and Lauren, J.G. 2005. Distribution of Arsenic in Soil, Water and Rice Plant in a Macro-Environment of the Command Area of Shallow Tube Well (STW). Proceedings of International Conference on Biogeochemistry of Trace Elements. Eds. Enzo. Lombi et. al. pp. 232-233.

Rahman, G. K. M. M.; Duxbury, J. M.; Ahmed, Z. U. and Lauren, J. G. 2013. Influence of flooding land type on soil arsenic level in Bangladesh. Proceedings of International Conference on the Biogeochemistry of Trace Element (ICOBTE). Georgia, USA. 0220-000227.

Rauf, M. A. 2009. Influence of Soil Arsenic on Yield and Arsenic Accumulation in Rice and Wheat. (Ph.D. Thesis). Department of Soil Science, Bangabandhu Sheikh Mujibur Rahman Agricultural University, Gazipur, Bangladesh.

Serre, M. L.; Kolovos, A.; Christakos, G. and Modis, K. 2003. An application of the holistochastic human exposure methodology to naturally occurring arsenic in Bangladesh drinking water. Risk Anal. 23, 51528.

SRDI, 2005. Manual of Land and Soil Resource Utilization. Soil Resource Development Institute. Ministry of Agriculture. Pupils Republic of Bangladesh.

Yu, W. H.; Harvey, C. M.; and Harvey, C. F. 2003. Arsenic in groundwater in Bangladesh: a geostatistical and epidemiological framework for evaluating health effects and potential remedies. Water Resour Res. 39, 1-7. 